\title{
Survival of patients receiving a liver transplant for hepatocellular carcinoma, and risk of tumor recurrence
}

\author{
D. Pérez de Luque, P. López Vallejos, J. L. Montero Álvarez, E. Fraga Rivas, P. Barrera Baena, G. Costán \\ Rodero, S. Rufian Peña, C. Díaz Iglesias, P. López-Cillero, J. Briceño Delgado, J. Padillo Ruiz, J. C. Pozo \\ Laderas $^{1}$, T. Marchal Molina², G. Solórzano Peck and M. de la Mata García
}

Unit of Digestive Diseases. 'Unit of Intensive Care. ${ }^{2}$ Service of Pathology. University Hospital "Reina Sofía". Córdoba, Spain

\begin{abstract}
Objective: the goal of this research has been to evaluate the survival, in long and short term, of the patient receiving liver transplant for hepatocellular carcinoma ( $\mathrm{HCC}$ ), the risk of posttransplant tumor relapse and factors related to this complication.

Design: retrospective study of a consecutive series of patients having had liver transplant for HCC.

Patients and methodology: transplant patients for $\mathrm{HCC}$ from 1989 to November 2003. Patients were selected due to general limitations of nodule size and quantity, which were subsequently published as Milan criteria. Also, criteria agreed in the Conference of Barcelona were followed in the pre-transplant diagnosis.

Results: the survival of this 81 patients group was of the 80, 61 and $52 \%$ for 1,5 and 10 years respectively. In the 32\% of the cases the HCC was an incidental finding in the explant. In the $12.3 \%$, the tumor relapse was verified. The multivariate research identified the size of the nodule (OR $=1,7944)(\mathrm{IC} 95 \%=$ $1,1332-2,8413)$ and the vascular invasion $(\mathrm{OR}=6,6346)$ (IC $95 \%=1,4624-30,1003)$ as risk factors of relapse.

Conclusions: the liver transplant in selected patients with HCC has good results in medium and long term. The risk of post-transplant tumor relapse becomes notably reduced and is associated with the size of the nodule and the microscopic vascular invasion.
\end{abstract}

Key words: Hepatocellular carcinoma. Liver transplant. Incidental tumors. Survival.

Pérez de Luque D, López Vallejos P, Montero Álvarez JL, Fraga Rivas E, Barrera Baena P, Costán Rodero G, Rufian Peña S, Díaz Iglesias C, López-Cillero P, Briceño Delgado J, Padillo Ruiz J, Pozo Laderas JC, Marchal Molina T, Solórzano Peck $G$, de la Mata García M. Survival of patients receiving a liver transplant for hepatocellular carcinoma, and risk of tumor recurrence. Rev Esp Enferm Dig 2006; 98: 899-906.

\section{Recibido: 04-11-05.}

Aceptado: 14-09-06.

Correspondencia: Daniel Pérez de Luque. C/ Gutiérrez de los Ríos, 18, escalera $2,1^{\circ}$ C. 14002 Córdoba. e-mail: danidiges@telefonica.net

\section{INTRODUCTION}

The HCC represents more than the $5 \%$ of the diagnosed tumors worldwide, and it is the fifth more frequent cancer in men and the eighth in women, causing 500.000 deaths per year (1).

The resection surgery and the liver transplant are the only therapeutic options with healing potentiality for HCC patients, but its applicability is very limited by the degree of the hepatic function and the size of the tumor. The resection surgery is the first therapeutic line but it is meant for small sized HCC and only nodule with a preserved hepatic function and without portal hypertension. In these patients, despite a careful selection, the rate of tumor recurrence after 3 years might exceed the $50 \%$ of the chances after 5 years (2).

With patients suffering unbalanced cirrhosis or multi-nodule HCC, the treatment to follow is the orthotropic hepatic transplant (OHT). These patients reach a survival rate of the $70 \%$ in 5 years, with a tumor recurrence inferior to the $15 \%$ when the candidates are selected by the Milan criteria (only nodule minor or equal to $5 \mathrm{~cm}$, or up to 3 nodules of $3 \mathrm{~cm}$ or less) $(3,4)$. The ablation of the tumor by means of percutaneous alcoholysis or radio frequency is included within the group of radical therapies by some authors, yet it bears a high rate of relapse and has considerable limits for its accessibility (5-7).

Another alternative in the treatment for $\mathrm{HCC}$ is the transarterial chemoembolization $(6,8)$, which has proved beneficial to patients with no healing options. This procedure can be applied in the pre-transplant period so as to prevent tumor growth, which is one of the causes for being excluded from the wait list in the 15$30 \%$ of the cases (9). The size and the quantity of the nodules and the reaction to the chemoembolization have been credited as determining risk factors of post-transplant tumor growth and relapse $(5,10)$. 
The prognosis for HCC has been established upon the basis of various classification systems (TNM, Okuda) which were reviewed in the European Association for the Study of the Liver (EASL) conference that was held in Barcelona in 2000. This event gave special importance to the prognostic value of the stages of tumor development, the degree of affectation of the hepatic function, the general state of the patient and the effectiveness of the treatment. These four variants are included in the current tumor phasing methods such as the Cancer of the Liver Italian Program (CLIP), which combines four variants and offers a seven-stage classification system; and the Barcelona Clinic Liver Cancer (BCLC), which also uses four variants but distinguishes only four stages in the tumor development (4).

We have retrospectively reviewed the results obtained from a wide group of patients who received a liver transplant for HCC in order to analyze their survival in long term and the factors that determine the risk of tumor relapse after the transplant.

\section{PATIENTS AND METHODS}

\section{Patients}

The sample for this retrospective study has been transplant patients for HCC from 1989 to 2003. Transplant indications for patients with HCC were strictly adapted to the Milan criteria since 1996 (11). Between 1989 and 1996 the selection of candidates had been made according to very similar limits, taken because of the generality of the transplant units (12). There were some cases in which a patient was excluded from the selection: if the tumor had a size bigger than $6 \mathrm{~cm}$; if there were 4 or more than 4 nodules; and those patients with signs of vascular invasion or extrahepatic dissemination $(3,4)$. Ever since 1996 only three patients with tumors of 5-6 cm were accepted in a wait list, having previously passed a chemoembolization session, which managed to get the tumor size reduced. For this research we have included those patients with histological diagnosis of HCC in the hepatic explant, unknown before the transplant (incidental HCC).

\section{Diagnosis}

The diagnosis of HCC follows the recommendations agreed in the conference about HCC that took place in Barcelona in 2000 (4), which unite histological criteria, high level of alphaphetoprotein and image techniques.

Before including the patient in a wait list, an exhaustive extension study (Doppler ecography, thoracic TC and bone gammagraphy) must be made so as to discard extrahepatic dissemination.

\section{Analyzed variants and statistic analysis}

The variants analyzed in this study are the following: age, sex, etiology of hepatopathy (C-virus, B-virus, alcohol and others), number of nodules, size of the biggest nodule (in the surgical piece), microscopic signs of invasion (vascular, capsular and lymphatic), tumor differentiation, patient death, cause of the death, time of development, tumor relapse and incidental tumor.

In this research a descriptive analysis of the series has been carried out. Student's T and Fisher's test have also been used. The analysis of the survival has been made according to Kaplan-Meier's method. Lastly, a univariate and multivariate logistic regression analysis has been performed in order to obtain the risk factors associated to post-transplant relapse. The research has been achieved using the statistics software SPSS version 8.1.

\section{RESULTS}

\section{Descriptive analysis}

Between 1989 and November 2003, 585 orthotopic liver transplants have been performed. Eighty one of them $(13,8 \%)$ were for patients with grafted HCC. In 55 of those patients $(67,9 \%)$ the tumor had been diagnosed before the transplant and confirmed in the explant. In the 26 remaining patients $(32,1 \%)$ the $\mathrm{HCC}$ was found after the histopathological study (incidental HCC). Nine patients were women $(11,1 \%)$ and 72 were men $(88,9 \%)$. The average age was $53,8 \pm 8,6$ with a range from 22 to 68 years old. The most relevant results from this group are exposed in table I.

The most frequent etiology for cirrhosis was the Hepatitis $\mathrm{C}$ virus (HCV), with a whole of 41 patients $(50,6 \%)$, followed by the alcohol (14 patients; $17,3 \%)$, then the hepatitis B virus (HBV) (9 patients; 11,1\%) and lastly other less frequent causes (17 patients; 20,1\%).

In 10 patients $(12,3 \%)$ tumor relapse occurred. Twenty eight from the 81 patients group $(34,6 \%)$ passed away, 9 cases $(32,1 \%)$ due to tumor relapse. One patient with HCC relapse still lives nowadays. Six patients died because of viral relapse $(21,4 \%)$, four by sepsis $(14,3 \%)$, and the rest by other causes such as primary graft dysfunction, chronic rejection, multiorganic failure, sudden death, myocardial infarction, cerebral hemorrhage, digestive hemorrhage due to varices and suicide.

\section{Analysis of survival}

The survival of this group of patients was of the $80 \%$ the first year after the transplant was performed. In the next years there would be a progressive decrease of this percentage, coming down to the $61 \%$ for 5 years and $52 \%$ for 10 (Fig. 1). The development of the patients with inci- 
Table I. Descriptive data of the sample

\begin{tabular}{|c|c|c|}
\hline Variables & $n$ & Percentage \\
\hline \multicolumn{3}{|l|}{ Incidental } \\
\hline Yes & 26 & 32.1 \\
\hline No & 55 & 67.9 \\
\hline \multicolumn{3}{|l|}{ Vascular invasion } \\
\hline Yes & 19 & 23.5 \\
\hline No & 62 & 76.5 \\
\hline \multicolumn{3}{|l|}{ Capsular invasion } \\
\hline Yes & 6 & 7.4 \\
\hline No & 75 & 92.6 \\
\hline \multicolumn{3}{|l|}{ Lymphatic invasion } \\
\hline Yes & 5 & 6.2 \\
\hline No & 76 & 93.8 \\
\hline \multicolumn{3}{|l|}{ Differentiation } \\
\hline Good & 30 & 37 \\
\hline Mild & 48 & 59.3 \\
\hline Poor & 3 & 3.7 \\
\hline \multicolumn{3}{|l|}{ Recurrence } \\
\hline Yes & 10 & 12.3 \\
\hline No & 71 & 87.7 \\
\hline \multicolumn{3}{|l|}{ Deaths } \\
\hline Yes & 28 & 34.6 \\
\hline No & 53 & 65.4 \\
\hline Uninodular & 42 & 51.9 \\
\hline Multinodular & 39 & 48.1 \\
\hline
\end{tabular}

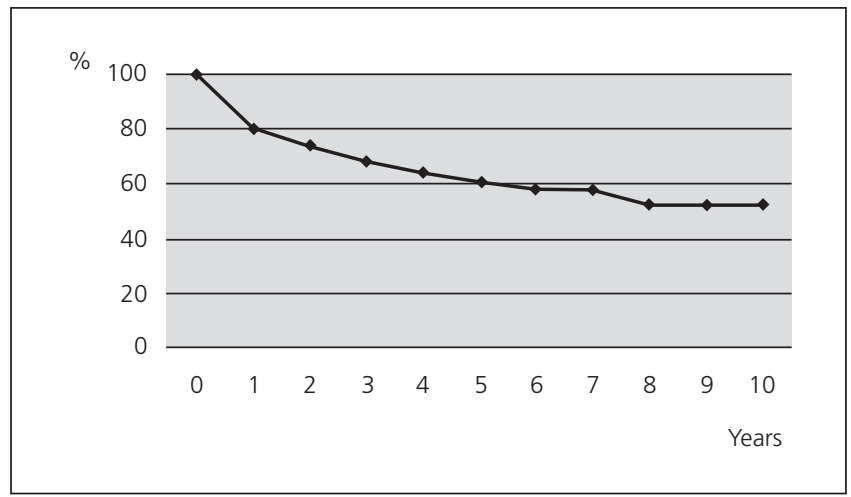

Fig. 1.- General survival curve of patients.

Curva de supervivencia general.

dental HCC was worse than those who had the HCC diagnosed before the transplant, with an average survival of $5 \pm 1,18$ and $7 \pm 1,35$ years respectively $(p=0,0386)$, but this factor turned out to have no statistic significance in the multivariate analysis.

Patients who experienced tumor relapse had a clearly unfavorable development and most of them passed away during the first three years after the transplant (Log-Rank $\mathrm{p}<0.05$ ) (Fig. 2).

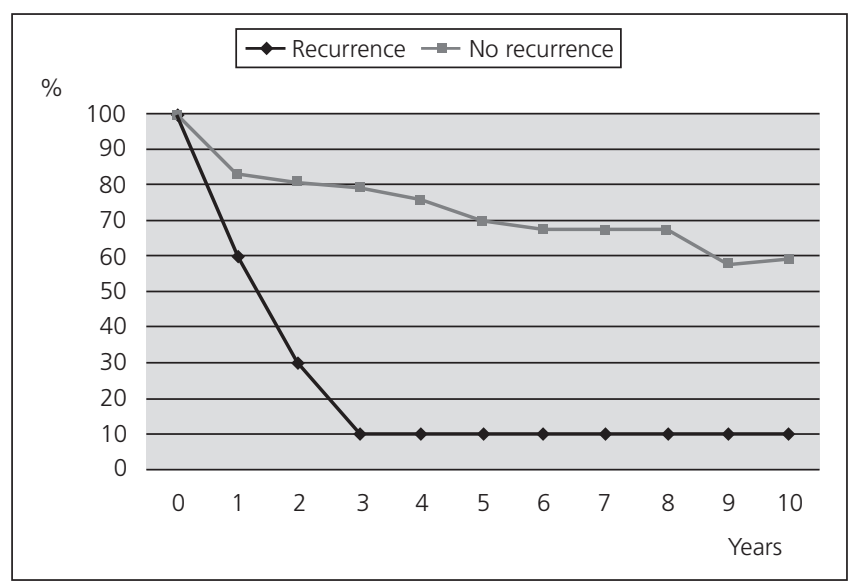

Fig. 2.- Survival rate according to tumor recurrence. Superviviencia según recidiva tumoral.

\section{Univariate analysis}

The univariate analysis of the risk factors of tumor relapse after transplant gave statistic significance to the vascular invasion, the size of the biggest nodule and the degree of histological differentiation. The lymphatic invasion reached only marginal significance but it was included in the multivariate study.

In relation to the degree of differentiation, it is appreciated that a pronounced decrease of the survival occurs when the tumors are poorly differentiated, with an average survival of $9 \pm 1,28$ years in the well differentiated tumors, $6,83 \pm 0,73$ years in the moderately differentiated ones, and 1,3 $\pm 0,68$ years in the poorly differentiated ones $(p=0,0107)$.

Patients with vascular invasion had higher rate of relapse $(p=0,007)$, which explains their low rate of survival.

The size of the nodule has also proved its statistic significance. According to Student's test, the risk of relapse was higher in patients with bigger tumors $(p=0,001)$ (Table II).

Table II. Variables with statistic significance in univariate analysis

\begin{tabular}{lcccc}
\hline & $B$ & Significance & $R$ & Exp (B) \\
\hline Vascular invasion & 1.9006 & 0.0078 & 0.2894 & 6.6901 \\
Nodular size & 0.6057 & 0.0092 & 0.2802 & 1.8325 \\
Lymphatic invasion & 1.7346 & 0.0787 & 0.1343 & 5.6666 \\
Differentiation & 2.0001 & 0.0160 & 0.2505 & 7.3896 \\
\hline
\end{tabular}

\section{Multivariate analysis}

The multivariate study by means of logistic regression (considering the post-transplant relapse of HCC as a dependent variable) identified the size of the nodule 
$(\mathrm{OR}=1,7944)(\mathrm{IC} 95 \%=1,1332-2,8413)$ and the vascular invasion $(\mathrm{OR}=6,6346)$ (IC 95\% $=1,4624-30,1003)$ as risk factors with independent nature (Table III).

Table III. Variable with statistic significance in multivariate analysis

\begin{tabular}{lccccc}
\hline & $B$ & Significance & $R$ & Exp (B) & IC 95\% \\
\hline Nodular size & 0.5847 & 0.0127 & 0.2639 & 1.7944 & $1.1332-2.8413$ \\
Vascular invasion & 1.8923 & 0.0142 & 0.2575 & 6.6346 & $1.4624-30.1003$ \\
Cte & -4.8134 & 0.0000 & & & \\
\hline
\end{tabular}

\section{DISCUSSION}

The HCC is the most frequent malignant tumor for the liver and it is clearly linked to the presence of hepatic cirrhosis. In the last few years there has been an important increase of its prevalence motivated by multiple factors, such as the higher survival of patients with cirrhosis, the development of the image techniques and the establishment of monitoring programs (13).

In Europe, the 85-90\% of the HCC appears upon hepatic cirrhosis (14-16). In this group of patients the liver transplant is the selected treatment (4). The high rates of tumor relapse described in the initial stages (32-54\%) and the consequent low rates of survival $(<40 \%$ in 5 years $)$ originated a review of the transplant criteria for these patients. The size and quantity of the nodules got limited and those cases with microscopic vascular invasion or extrahepatic dissemination were discarded for transplant. This clinic practice got consolidated in the so-called Milan criteria $(11,17,18)$, which made it possible to communicate survival rates of the $70 \%$ for 5 years and percentages of relapse inferior to $15 \%(3,4,18)$, very similar numbers to those obtained in our research.

The cause of death in 9 patients was tumor relapse (32\% in this group). The second cause of decease was viral relapse, due especially to the $\mathrm{C}$-virus. These data are similar to those published by other authors (19).

The incidence of previously unknown HCC (incidental HCC) is quite variable. It depends on the bibliography and it oscillates between 15 and 50\% (19-22). In the sample of our hospital it has been $32,1 \%$. In spite of being described as a lower survival for incidental HCC patients, this condition has not been proved significant in the univariate and multivariate analyses.

Patients with tumor relapse see their survival drastically reduced. The univariate analysis reveals three parameters associated to this complication: the microscopic vascular invasion, the size of the nodules and the histological differentiation. These variables have been already validated and cited as risk factors by other authors (13,19, 23-25). In the multivariate analysis, only the size of the nodules and the vascular invasion have been proved to be independent risk factors, as some other authors have already said
$(13,19,23,26)$. The microscopic vascular invasion is a high risk factor of tumor relapse. It has been associated to the decrease of survival and must be considered as a key element in the development of strategies that prevent relapse after the transplant (26). In fact, some studies have been aimed to find markers that help in selecting patients with a high risk of vascular invasion (27).

The size of the nodules has been considered by some authors as a way to predict relapse and survival $(28,29)$, yet in other groups it has not been possible to establish this relationship, partly due to problems of sample size $(13,30)$. It must be taken into account that the size of the nodules analyzed in this study was obtained from the explant. This increases the accuracy of the analysis of the interaction between size and risk of relapse, but its value remains aside due to the discrepancies about the image techniques, in which the tumor stages are generally underestimated.

To sum up, the results of this study prove that with the current criteria for selecting candidates the tumor relapse is not very frequent. The microscopic vascular invasion and the size of the nodules allow predicting reliably a higher risk of recurrence. This group of patients with bad prognosis can take benefit from more suitable guidelines of immunosuppression within the frame of controlled clinic studies and a more intensive clinic monitoring.

\section{REFERENCES}

1. Bosch FX, Ribes J, Cleries R, Díaz M. Epidemiology of hepatocellular carcinoma. Clin Liver Dis 2005; 9 (2): 191-211.

2. Arii S, Yamaoka Y, Futagawa S, Inocue K, Kobayashi K, Kojiro M, et al. Results of surgical and nonsurgical treatment for small-sized hepatocellular carcinomas: a retrospective and nationwide survey in Japan. Hepatology 2000; 32: 1224-9.

3. Llovet JM, Fuster J, Bruix J. Intention-to-treat analysis of surgical treatment for early hepatocellular carcinoma: resection versus transplantation. Hepatology 1999; 39: 1434-40.

4. Bruix J, Sherman M, Llovet JM, Beaugrand M, Lencioni R, Christensen E, et al. Clinical management on hepatocellular carcinoma. Conclusions of the Barcelona-2000 EASL Conference. J Hepatol 2001; 35: 421-30.

5. Varela M, Sanchez W, Bruix J, Gores GJ. Hepatocellular carcinoma in the setting of liver transplantation. Liver Transp 2006; 12: 1028-36.

6. Bruix J, Sherman M, Practice Guidelines Committee, American Association for the Study of Liver Diseases. Management of hepatocellular carcinoma. Hepatology 2005; 42 (5): 1208-36.

7. Calleja Kempin J, Colón Rodríguez A, Muro de la Fuente A, Clemente Ricote G, Prieto Martín M, Santos Castro L, et al. Tumoral response factors after radiofrequency ablation of hepatocellular carcinoma in cirrhotic liver. Rev Esp Enferm Dig 2005; 97 (10): 688-98.

8. Llovet JM, Bruix J. Systematic review of randomized trials for unresectable hepatocellular carcinoma: Chemoembolization improves survival. Hepatology 2003; 37 (2): 429-42.

9. Yao FY, Bass NM, Nikolai B, Merriman R, Davern TJ, Kerlan R, Ascher NL, Roberts JP. A follow-up analysis of the pattern and predictors of dropout from the waiting list for liver transplantation in patients with hepatocellular carcinoma: implications for the current organ allocation policy. Liver Transpl 2003; 9 (7): 684-92.

10. Shimoda M, Ghobrial RM, Carmody IC, Anselmo DM, Farmer DG, Yersiz H, et al. Predictors of survival after liver transplantation for hepatocellular carcinoma associated with Hepatitis C. Liver Transpl 2004; 10 (12): 1478-86. 
11. Mazzaferro V, Regalia E, Doci R, Andreola S, Pulvirenti A, Bozzetti F, et al. Liver transplantation for the treatment of small hepatocellular carcinomas in patients with cirrhosis. N Engl J Med 1996; 334 (11): 693-9.

12. Bismuth H, Chiche L, Adam R, Castaing D, Diamond T, Dennison A Liver resection versus transplantation for hepatocellular carcinoma in cirrhotic patients. Ann Surg 1993; 218 (2): 145-51.

13. Martínez Ares D, Suárez López FJ, Souo Ruzo J, Otero Ferreiro A, Gómez Gutiérrez M, González Conde C, et al. Liver transplantation in patients with hepatocellular carcinoma: factors implicated in tumor relapse. Rev Esp Enferm Dig 2004; 96: 22-31.

14. Chevret S, Trinchet JC, Mathiu D, Rached AA, Beaugrand M, Chastang C. A new prognostic classification for predicting survival in patients with hepatocellular carcinoma. J Hepatol 1999; 31: 133-41.

15. Barbara L, Benzi G, Gaiani S, Fusconi F, Zironi G, Siringo S, et al. Natural history of small untreated hepatocellular carcinoma in cirrhosis: a multivariate analysis of prognostic factors of tumor growth rate and patient survival. Hepatology 1992; 16: 132-7.

16. Llovet JM, Bustamante J, Castells A, Vilana R, Ayuso MC, Sala M, et al. Natural history of untreated nonsurgical hepatocellular carcinoma: rationale for the design and evaluation of therapeutic trials. Hepatology 1999; 29: 62-7.

17. Ringe B, Pichlmayr R, Wittekind C, Tusch G. Surgical treatment of hepatocellular carcinoma: experience with liver resection and transplantation in 198 patients. World J Surg 1991; 15: 270-85.

18. Moreno P, Jaurrieta E, Figueras J, Benasco C, Rafecas A, Fabregat J, et al. Orthotopic liver transplantation: treatment of choice in cirrhotic patients with hepatocellular carcinoma?. Transplant Proc 1995; 27: 2296-8.

19. Pérez Saborido B, Loinaz Segurola C, Gimeno Calvo A, Meneu Díaz JC, Abradelo de Usera M, Calvo Pulido J, et al. Liver transplantation for hepatocellular carcinoma: our experience from 1986. Transplant Proc 2003; 35 (5): 1825-6.

20. Cho CS, Knechtle SJ, Heisey DM, Hermina M, Armbrust M, D'Alessandro AM, et al. Analysis of tumor characteristics and survival in liver transplant recipients with incidentally diagnosed hepatocellular carcinoma. J Gastrointest Surg 2001; 5 (6): 594-601.

21. González-Uriarte J, Valdivieso A, Gastaca M, Errasti G, Campo M, Hernández MJ, et al. Liver transplantation for hepatocellular carcinoma in cirrhotic patients. Transplant Proc 2003; 35 (5): 1827-9.

22. Ackhar JP, Araya V, Baron RL, Marsh JW, Dvorchik I, Rakela J. Undetected hepatocellular carcinoma: clinical features and outcome after liver transplantation. Liver Transpl Surg 1998; 4 (6): 477-82.

23. Klintmalm GB. Liver transplantation for hepatocellular carcinoma: a registry report of the impact of tumor characteristics on outcome. Ann Surg 1998; 228 (4): 479-90.

24. Iwatsuki S, Dvorchik I, Marsh JW, Madariaga JR, Carr B, Fung JJ, et al. Liver transplantation for hepatocellular carcinoma: a proposal of a prognostic scoring system. J Am Coll Surg 2000; 191 (4): 389-94.

25. Tamura S, Kato T, Berho M, Misiakos EP, O’Brien C, Reddy Kr, et al. Impact of histologic grade of hepatocellular carcinoma on the outcome of liver transplantation. Arch Surg 2001; 136: 25-30.

26. Chau GY, Lui WY, Wu CW. Spectrum and significance of microscopic vascular invasion in hepatocellular carcinoma. Surg Oncol Clin N Am 2003; 12 (1): 25-34.

27. Salizzoni M, Romagnoli R, Lupo F, David E, Mirabella S, Cerutti $\mathrm{E}$, et al. Microscopic vascular invasion detected by anti-CD34 immunohistochemistry as a predictor of recurrence of hepatocellular carcinoma after liver transplantation. Transplantation. 2003; 76 (5): 844-8.

28. Roayaie S, Schwartz JD, Sung MW, Emre SH, Miller CM, Gondolesi $\mathrm{GE}$, et al. Recurrence of hepatocellular carcinoma after liver transplant: patterns and prognosis. Liver Transpl 2004; 10 (4): 534-40.

29. Grasso A, Stigliano R, Morisco F, Martines H, Quaglia A, Dhillon $\mathrm{AP}$, et al. Liver transplantation and recurrent hepatocellular carcinoma: predictive value of nodule size in a retrospective and explant study. Transplantation 2006; 81 (11): 1532-41.

30. Frilling A, Malago M, Broelsch CE. Current status of liver transplantation for treatment of hepatocellular carcinoma. Dig Dis 2001; 19 (4): $333-7$ 